\title{
Application of seismic tomography for detecting structural faults in a Tertiary Formation
}

\author{
Victor A. Rinaldi ${ }^{1, *}$, Horacio V. Ibarra ${ }^{2}$, Ricardo F. Viguera ${ }^{3}$, and Juan C. Harasimiuk ${ }^{3}$ \\ ${ }^{1}$ National University of Córdoba, Civil Engineering Department, 1611 Vélez Sársfield Ave., Argentina \\ ${ }^{2}$ Louis Berger Group Inc., Panama \\ ${ }^{3}$ CIM Group Inc., Panama
}

\begin{abstract}
Seismic refraction technique is an increasingly useful geophysical tool for geotechnical studies in civil engineering work including the mapping of different soil formation of subsoil and detection of the bed rock. Additionally, wave velocity is a key parameter which correlates directly with significant geotechnical parameters of soils and rocks. Today, the evolution of the measurement technique in the field and the data processing allows to obtain tomographic images which increases its potential for applications to evaluate structuration of rock mass. This work describes the basic principles of seismic tomography and a case history of an application in civil works used to detect hidden faults in the sedimentary Gatun formation at the north of Panama. The correlation between the seismic profile and geologic profile obtained from boreholes showed very good agreement. Subsequent directed boreholes performed at the site confirmed the position and nature of the faults detected.
\end{abstract}

\section{Introduction}

The seismic refraction method is based on travelling of the elastic compression wave through geological media by using various sensors which are displayed equally spaced along a survey line. Elastic waves are generated at the ends and intermediate points by means of hammers, mass falls, guns, or even explosives for deep prospection. These waves are detected by sensors called geophones that measure the vibration velocity when the elastic wave reach the point where they are located. In general, 12, 24 or 48 geophones are usually displayed along the survey line. The spacing between geophones and length of the survey line depend on the required depth of exploration. As a roughly approximated rule, exploration depth ranges between $1 / 4$ and $1 / 3$ of the total length of the line. The signal captured by the geophones is conditioned (eg. Amplified and filtered) by a seismograph that also allows for displaying and recording the signals of all the geophones arranged along the lines. The time of arrival of the compression waves at each geophone is determined from the records and the space-time curves are then obtained. The analysis of these curves allow determine the seismic profile. The most common methods of interpretation of time-space curves are: intercept times, apparent velocities, wavefronts, delay times and the general reciprocal method [1-3]. Today, increasingly advances in sophisticated computational methods, allowed the development of tomographic processing algorithms of refraction. These algorithms allow to solve variations or velocity gradients in depth and lateral changes in highly variable sites such as due to the presence of voids, faults, karst for example. Tomographic images generally show gradual variations of wave velocities with depth oppositely to that obtained in the traditional interpretation methods where layers with different constant velocities are identified. The limitations of gradual velocity variations are discussed in [4]. In sedimentary environments where the propagation velocity increases with depth due to the change of confinement, the gradual variation of speed is more realistic than that obtained with a multi-layer model. The opposite can be understood in environments with harsh shifting such as sediment overlaying the bed rock or interlayers that occur due to the presence of water or stiff cemented soils.

The seismic refraction method has numerous applications in geotechnical engineering field including: the mapping of the stratigraphy of a site, determining the location of the bed rock and the water table, Evaluation of the degree of fracturing and weathering and of the rock, detection of geological faults and degree of compactness and cementation of sedimentary layers, the evaluation of dynamic soil parameters for use in seismic designs and more recently the determination of geotechnical parameters for foundation design. Probably the biggest limitation of seismic refraction is that requires that the stiffness of the layers increase in depth. The presence of any inclusion with lower stiffness can be misinterpreted. This work describes an application of the tomographic technique used to evaluate the faulting of the bed rock in the Tertiary Gatun Formation in a section performed across the Rio Chagres located at the north side of

\footnotetext{
*orresponding author: vrinaldi@unc.edu.ar
} 
Panama. The results were thereafter validated by directed boreholes, which also allowed to evaluate the applicability of the method and recognize its limitations.

\section{Localization and geology}

Figure 1 shows the location of the Rio Chagres close to the town of Colon, northwest of Panama, on the Atlantic coast side. The Isthmus of Panama is formed by the rigid block (often referred to as the micro plate Panama), located between the tectonic plates of Cocos and Nazca south, the Caribbean plate north and plaque South east America. It is part of the volcanic arc of Central America originated in the Miocene about 17 million years ago. The continuous movement of North America and South America, being at about $25 \mathrm{~mm} /$ year, is responsible for the internal deformation of the isthmus which translates into folds and interior faulting [5]. The predominant directions of faults are parallel to the Panama Canal in the direction northwest-southeast and some direction Northeast-Southwest [5] with high degree of dip [6]. The most recognized faults among the first are Limon and Pedro Miguel and among the second is the Rio Gatun. Figure 2 shows the faulting study from Pratt [6]. Notice the possible structural control of the faults on the course of the Rio Chagres. Despite the complexity tectonism described, a very low actual seismic activity is recognized, although, such information creates a significant uncertainty in seismic risk assessment in Panama.

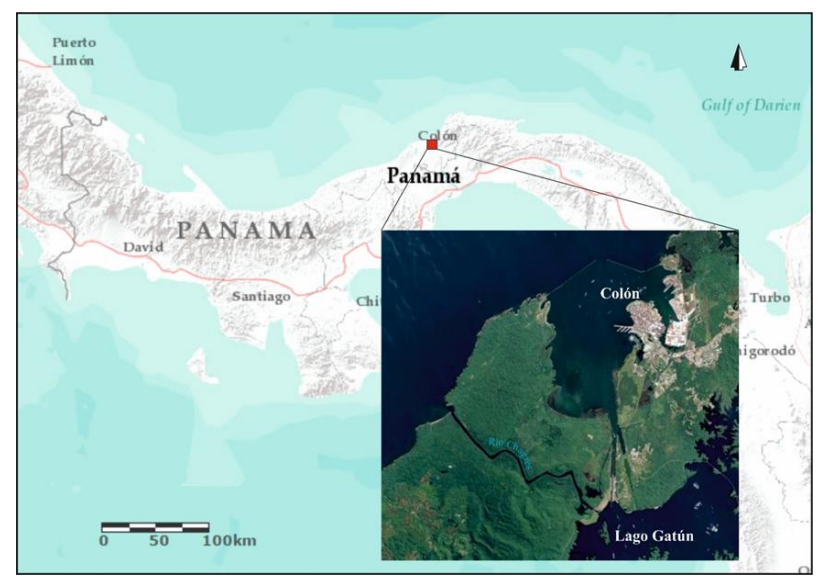

Fig. 1. Localization map of the sector of study.

The general stratigraphy of the sector of interest has been extensively described by Jones [7] and Woodring [8] which mainly consist on Miocene and Holocene deposits overlaying the Pre-Tertiary volcanic formations. The deepest sedimentary deposit is the Gatun Formation. This Formation is composed of alternating sequences of sandstone, siltstone, conglomerate and marine peats. It is gray-green in color, with a gentle dip to the northwest. Formation contains content of macro and micro fossils in very good condition of preservation. It has an estimated maximum thickness of about $500 \mathrm{~m}$ with an approximate elevation of $+100 \mathrm{~m}$ in southern Limon Bay and reduces its elevation below sea level to the Caribbean coast. The Chagres Formation over the Gatun Formation, consists of massive sandstone, siltstone and some element found in its base identified as Toro limestone.

The Atlantic Muck is the most recent Quaternary sediments of the Pleistocene and Holocene, which overlap to the formation Gatun, filling basins and channels created by erosion. Thus, the Atlantic muck is widely distributed in the Gatun Lake area between the north shore of the lake and Gamboa. This includes the Chagres River and Gatun Trinidad valleys associated with the interior and coastal wetlands areas with thicknesses that can reach $80 \mathrm{~m}$ deep. The Atlantic Muck consists of clays, silts and fine sands with abundant organic matter highly saturated.

The topography of the area of interest has a smooth slope dipping towards the north, essentially as the result of the progressive sedimentation, in contrast to erosion processes involved in adjacent areas. In a relatively recent geological period, the surface of the earth was higher than today and the most important rivers of the Atlantic generated deep valleys. Following a period of subsidence, it caused a reduction in the speed of currents, with the resulting deposition of silt and plant debris. Sea periodic invasions generates depositions in salty water conditions of marine sediments. The last movement in the coastal area of the Atlantic raised surfaces a few feet above sea level.

\section{Works performed}

The geophysical study across the Chagres River was carried out as part of a program required for evaluating the geotechnical conditions for the foundation of a bridge. Figure 2 shows the geographical location of the Chagres River and the location of the projected bridge crossing in the vicinity of the Atlantic coast. The geotechnical program included geophysical studies and drilling. A total of 33 rotary drills were made up to a maximum depth of $117 \mathrm{~m}$ at the place of each of the bridge piers. The geophysical studies consisted of a seismic line using the refraction technique along the axis of the bridge, downhole (DH) tests and spectral analysis of surface waves (MASW) were also conducted at the site.

In this work, 5 seismic lines of $115 \mathrm{~m}$ in length each were performed along a total of approximately $840 \mathrm{~m}$ of coverage. For this work, a Geode 24 device from Geometrics was used. Each of the survey lines was performed using a total of 24 geophones with separations $5 \mathrm{~m}$. The geophones were fixed to the soil by means of inserts of $8 \mathrm{~cm}$ in length. For each seismic line, 5 shots were made at both ends, at the quarters and at the center. In addition, measurements were taken with long distance shots corresponding to the opposite bank of the river in lines 1, 2, 3 and 4, to obtain information of soil layers below the river. The energization at each point was made using a pressurized gas cannon system. This system allowed to increase the impact energy with respect to a manually driven mass and therefore increase the penetration depth (no explosives were allowed to be used at the site). Figure 3 displays a picture of the gas cannon described. To cover the section of the river, without using hydrophones, the lines were placed on the margins and 
alternately was shooting from the margins opposite the lines.

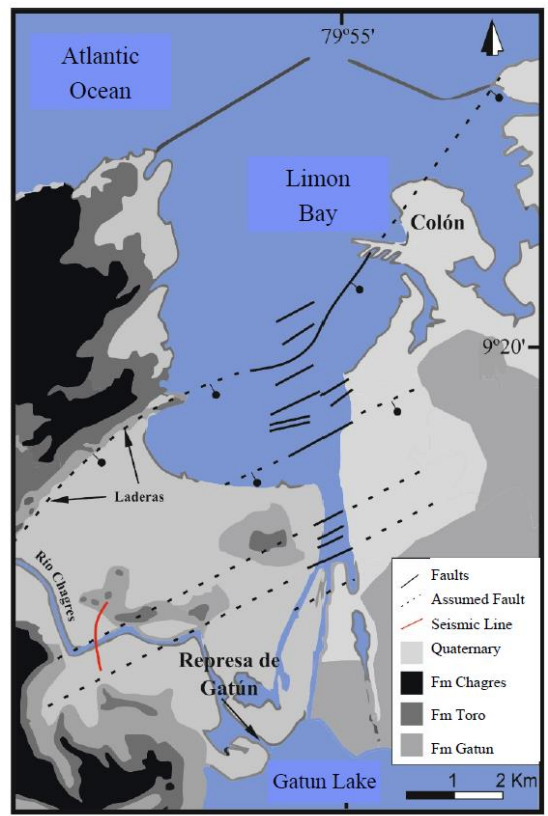

Fig. 2. Map of Panama with the main direction of faults. (modified from Pratt [5]). Red line shows the location of the seismic line.

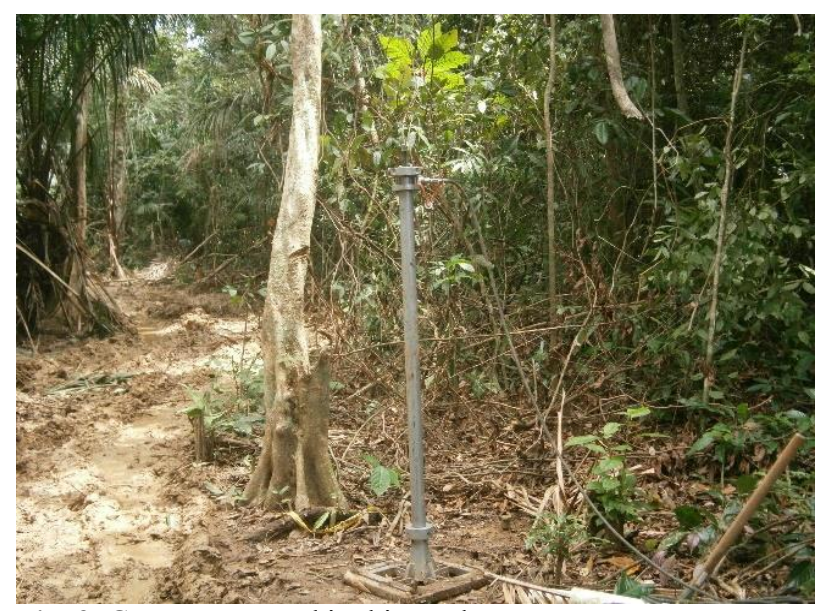

Fig. 3. Gas cannon used in this work

Field records obtained were processed and interpreted using the computer programs Plotrefa, and Pickwin from Geometrics. For the data processing the following steps were used:

A. Detailed study of the records: Records were studied signal by signal, in order to assess the quality of them and consistency.
B. Processing Records: The raw signals obtained were filtered in bandwidth sensors, in order to remove line noise, odd measurements.

C. Detection of Arrivals: From the records processed, the arrival times of the compression waves were determined. The detection of these points was initially performed by the computer program Pickwin and thereafter checked manually.

D. Plotting Profiles: With the first arrivals curves space-time are plotted as shown in Figure 4.

E. Obtaining seismic profiles: From the analysis of the space-time curves, the cross sections were obtained. For this operation, the processing software Plotrefa from Geometrics was used. The program uses the routine of least squares minimization in order to approximate the time model calculated with that measured in the field.

F. Interpretation of Seismic Profile: The seismic profile was interpreted using a program that allows generic images tracing dividing lines and signs.

\section{Results}

The tomography that results of composing and processing the five seismic lines all together is shown on Figure 5. The seismic tomography obtained presented a mean square error RMS $=17.64 \%$ being a little higher than the desirable limit of $5 \%$. However, the boundaries and transitions between layers were consistent with those obtained from boreholes.

The tomography shows a profile of increasing wave velocity with depth. Unconsolidated sediments to slightly consolidated and saturated are related to propagation velocities of $500 \mathrm{~m} / \mathrm{s}$ and up to $1000 \mathrm{~m} / \mathrm{s}$. Notice that even this layer is saturated, the measured maximum velocity is lower than that of the water $(1500 \mathrm{~m} / \mathrm{s})$. Such effect may be attributed to the presence of large amount of gas bubbles in the soil arising from de decomposition of organic matter. Gas bubbles can be observed directly when escaping from drilled boreholes. The upper soft layer increases its thickness as one moves away to the margins of the floodplain river. Materials with larger sand content and higher level of structuration yield propagation velocity values between $1000 \mathrm{~m} / \mathrm{s}$ and $1800 \mathrm{~m} / \mathrm{s}$. Propagation velocities between $1800 \mathrm{~m} / \mathrm{s}$ and $2500 \mathrm{~m} / \mathrm{s}$ are associated to the Gatun formation. The lower limit is consistent with the weathered and fractured rock. Propagation velocities greater than $2500 \mathrm{~m} / \mathrm{s}$ are attributed to a rock in good structural condition. 


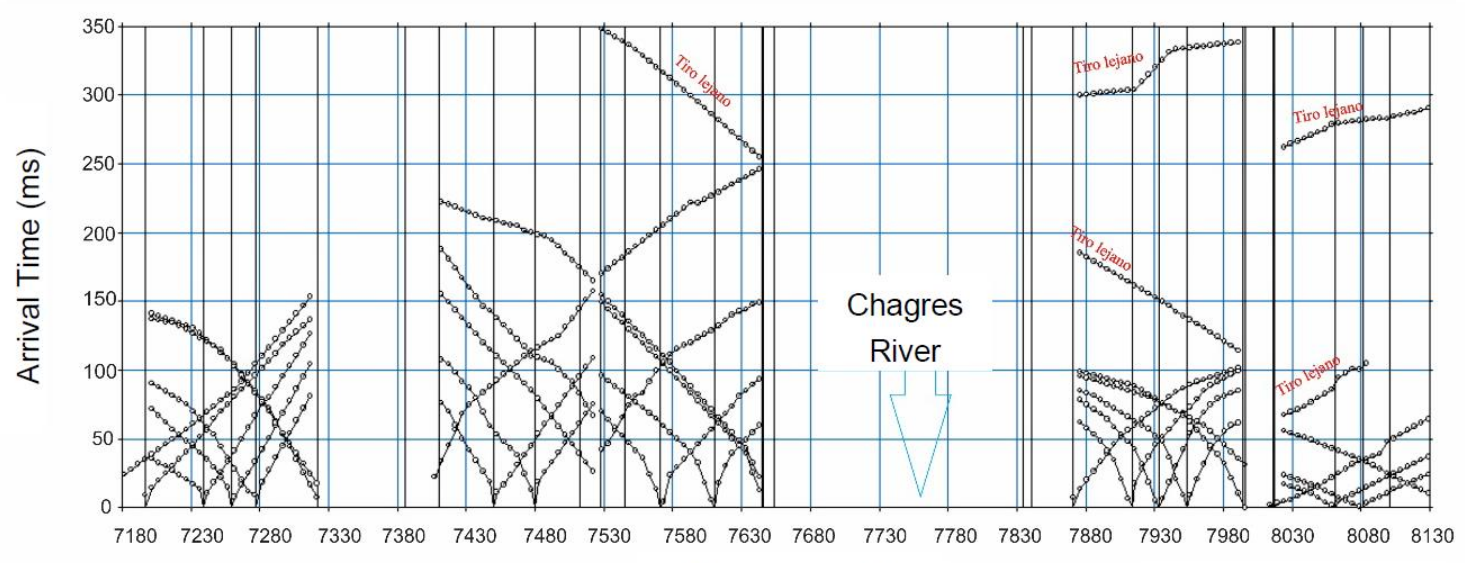

Progressive $(\mathrm{m})$

Fig. 4. Space-time curves obtained in this work using 5 seismic lines along the $840 \mathrm{~m}$ of exploration section. Filled lines correspond to the model response.

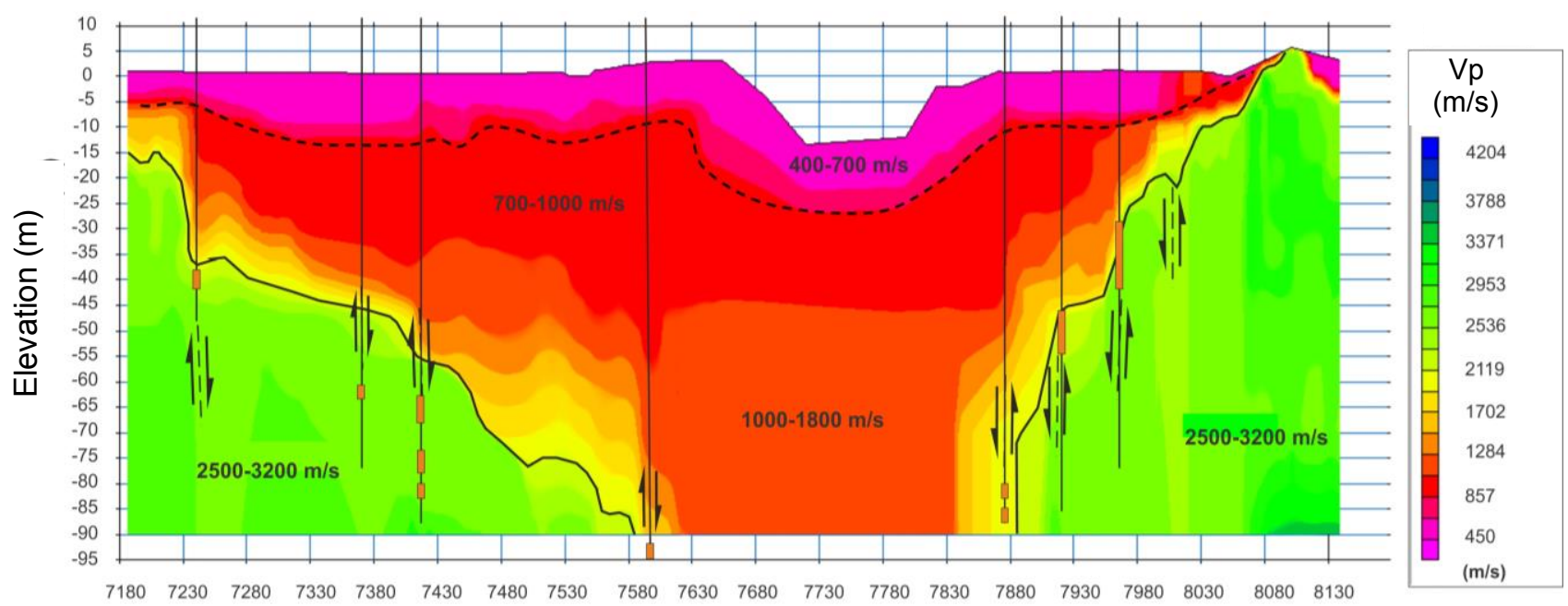

Progresive $(\mathrm{m})$

Fig. 5. Tomography obtained from the processing of the five seismic lines performed in this work.

An advantage of this method is to allow visualization of variation in the stratigraphic in both vertical and horizontal directions. In the tomography image of Figure 5 , it is also shown vertical discontinuities observed in the Gatun formation indicated by mean of shear arrows and attributed here to multiple faults detected. The direction of the arrows shows the direction of displacement of the blocks. The existence of the faults was thereafter confirmed by directed boreholes. The discontinuities are filled with brecciated sandstone, medium to coarse grained, with a high degree of weathering, completely fractured and with high contents of shells. In some sectors the discontinuities are composed of alternating layers of calcareous tufa and fine sand and silty. Seven zones of normal fault type were identified, corresponding to a structure of Graven type, due to regional extensional stresses. In the river zone it has not been observed the presence of a reflector of high velocity to the depth reached by this study of approximately $90 \mathrm{~m}$. It is estimated that this lack of reflector may be due to the presence of faults or lateral discontinuities on the banks of the river that did not allow the passage of the wave train or a high degree of fractured of rock. This zone could be described as a sector where a possible failure of important magnitude develops.

\section{Conclusions}

This work presented the result of the seismic survey in a sedimentary formation using the methodology of the tomography acquisition and data processing. The main result of the work done is the tomographic image of the cross section presented on Figure 5. From this results, the following conclusions can be highlights:

a) The geophysical methodology proposed to evaluate the site performed adequately, even though the desirable accuracy of $5 \%$ could not be reached due to the many difficulties that presented the surface conditions at the site.

b) The tomography cross section at the site allows to evaluate the variation with depth of the various layers associated to different compression wave velocities. The most relevant 
interphase was that of the bedrock corresponding to the Gatun Formation.

c) The tomography image allows also distinguish vertical discontinuities that were related here to faults. These vertical faults were then verified using directed boreholes.

d) An interesting observation is the wave propagation velocity obtained for the Atlantic Muck, which was much lower than that of the water. This lower value was attributed here to the presence of gas bubbles due to the high organic matter content.

We thank Louis Berger Group Inc. Company for allowing us the publication of the data presented here.

\section{References}

1. A. Sarria Molina, Ediciones Uniandes, Santa Fe de Bogotá, Colombia, pp. 300, (1996).

2. B. B. Redpath, U.S. Army Engineer Waterways Experiment Station Explosive Excavation Research Laboratory, Technical Report E-73-4, Livermore, California, 51 p (1973).

3. P. Kearey, M. Brooks, I. Hill, Blackwell Science Ltd., Osney Mead, Oxford, P. 281, (2002).

4. M. L. Rucker, Proceedings of the Geophysics 2002 conference, Los Angeles, California, p.11, (2002).

5. T. Rockwell, R. Bennett, E. Gath, P. Francesci, Tectonics 61 (4), (2010).

6. L. T. Pratt, M. Holmes, E. Schweig, J. Gomberg, H. A. Cowan, Tectonophysics 368, 211-227, (2003).

7. S. R. Jones, Geological Society of America Bulletin 61, 893-922, (1950).

8. W. P. Woodring, United States Geological Survey Professional Paper 306-A, (1957). 